\title{
ARTICLE
}

\section{Young people who cut themselves: can understanding the reasons guide the treatment?}

\author{
Barry Wright, Naomi Hooke, Stephan Neupert, Chan Nyein \& Suzy Ker
}

Barry Wright is Professor of Child and Adolescent Psychiatry in York, UK. Naomi Hooke is a child mental health research assistant in York, UK. Stephan Neupert is a consultant child and adolescent psychiatrist in Saxony, Germany.

Chan Nyein is a specialty registrar in psychiatry at Northwick Park, UK. Suzy Ker is a consultant in working age adult psychiatry in Harrogate, UK. Correspondence Professor Barry Wright, Consultant Child and Adolescent Psychiatrist, Lime Trees Child and Family Unit, 31 Shipton Road, York Y030 5RE, UK. Email: barry.wright1@nhs.net a. Key references only are cited in this article. Sources consulted but not mentioned in the text are listed in the Appendix.

\begin{abstract}
SUMMARY
Young people who cut themselves may do so for reasons that go beyond diagnosis. Relevant processes include responses to trauma, coping, emotion regulation and cultural identification. Some clinicians regard those who self-harm negatively or consider one therapeutic approach to be suitable for all. This article explores the possible mechanisms involved when young people cut themselves and discusses therapeutic approaches in the light of these. Clinicians and researchers are encouraged to refine, develop and research interventions for young people who self-harm by cutting.

\section{DECLARATION OF INTEREST}

None.
\end{abstract}

This article seeks to promote a dialogue about designing interventions that move away from a homogenised approach to young people who cut themselves. Young people themselves are asking for this (Storey 2005). The act of cutting one's skin is not a diagnosis in its own right and the behaviour continues to attract stigma from public and professionals alike (Saunders 2011). We explore the literature ${ }^{a}$ examining the reasons why young people cut themselves. We then consider how this might guide the choice of interventions and directions for future research.

\section{Terminology}

Many terms have been used over the years for those who cut their own skin. The direct destruction or alteration of body tissue, usually without conscious suicidal intent, has been described as self-mutilation (Favazza 1998), self-injury (Nock 2010) and nonsuicidal self-injury (NSSI) (Andover 2012). Here, we refer to it simply as 'cutting'. Where possible, we have drawn on research specific to adolescents presenting with cutting. Where the literature on cutting is sparse, we have referred to self-harm research more broadly. We recognise that there is an ongoing debate about terminology. Andover et al
(2012) give a good account of this. One of the points they make is that current nomenclature invariably leads to heterogeneous groups and these are not helpful clinically. We therefore seek to explore cutting and understand individual motivation as a driver for treatment. Although we recognise its importance, it is not our intention to focus on nomenclature.

\section{Prevalence}

Box 1 summarises key studies showing rates of self-harm and mutilation among young people in various countries.

\section{Stigma and heterogeneity}

Ideally, any young person who presents to services having cut themselves should be offered a full assessment by a mental health professional (Hawton 1996; National Institute for Health and Clinical Excellence 2004). Cutting by a young person provokes a range of attitudes and thoughts in healthcare professionals, some of which are negative (Friedman 2006). A recent Young Minds report (2012) in the UK suggests that up to $50 \%$ of professionals struggle to empathise with or understand young people who self-harm. Other research found that some young people who received care from counsellors or clinicians felt that they were not listened to (Storey 2005). The role of health professionals is to improve the health trajectory of the young person, so they need to understand what is going on and how they might help.

Some clinicians have a tendency to consider young people who cut their own skin as one homogeneous group (Jeffery 2002). Research suggests that some professionals see both adults and young people who self-harm as 'attention-seeking' (Taylor 2009; Saunders 2011), and many divide them into subgroups such as 'the worthy depressed' and those with personality disorders (McAllister 2003). Unfortunately, these subcategories are not helpful in terms of designing support and therapies to help young people move forward developmentally into a healthier trajectory. 
BOX 1 Rates of self-harm and cutting among young people

Estimated incidence of cutting: between 0.7 and 7\% (Favazza 1989; Hawton 2002)

Lifetime prevalence of self-harm among 6020 15- and 16-year-old pupils in 41 comprehensive, grammar and independent schools in England: 7\%; two most commonly reported methods: self-cutting $(64.6 \%)$ and self-poisoning (30.7\%); only $12.6 \%$ had gone to hospital as a result (Rodham 2004) Retrospective study of adults and adolescents in the UK comparing 428 people who cut themselves with 11065 who took overdoses of medication: those who had cut were more likely to be male, live alone, misuse alcohol and have low suicidal intent (Hawton 2004)
Lifetime prevalence of cutting in a school-based survey in the north of England: $23 \%$ 'at least once' (Hall 2010a)

Proportion of 5604 15- and 16-year-olds from Scotland and Ireland who reported acts of selfharm: 11.4\% (O'Connor 2012)

Lifetime prevalence of cutting among 245 American university students: $13.8 \%$ (Favazza 1989)

Lifetime prevalence of cutting among over 4000 Finnish 13- to 18-year-olds: $11.5 \%$; current cutting: 1.8\% (Laukkanen 2009)

1-year prevalence of self-harm (including methods such as deliberate reckless driving) in 1699
Australian 15- to 16 -year-olds: $5 \%$; significantly more girls reported cutting (Patton 1997)

Lifetime prevalence of 'self-mutilation' in community sample of 352 South Australian young people: $9 \%$; no difference in prevalence between boys and girls (Martin 1995)

Lifetime prevalence of self-harm among 1800 Australian teenagers: $10 \%$ of girls, $6 \%$ of boys; large reductions in this behaviour on entering young adulthood (Moran 2012)
The most pressing question facing the clinician is the nature of care a young person and their family should receive to improve the young person's mental health. Neither the act of cutting itself nor the broad terminology used to describe it (e.g. NSSI or selfharm) gives any reliable pointer as to what type of therapeutic support to provide. A unified approach to understanding cutting is unlikely to be helpful; for example, a depressed and suicidal young person may need quite different interventions from a young person who is cutting as part of a peer culture.

\section{Why do young people cut themselves?}

In a study of 6020 English teenagers (Rodham 2004), those who had harmed themselves in any way $(n=398)$ were asked to describe in their own words why they thought they had done so. They were also asked to choose from a list of eight reasons that had been drawn up from previous research (Box 2). Eighteen per cent gave the spontaneous reason for

\section{BOX 2 List of reasons young people chose from to explain why they cut themselves ${ }^{a}$}

- I wanted to get relief from a terrible state of mind

- I wanted to punish myself

- I wanted to die

- I wanted to show how desperate I was feeling

- I wanted to find out if someone really loved me

- I wanted to get some attention

- I wanted to frighten someone

- I wanted to get my own back on someone

a. The first four on this list are the reasons most commonly chosen in the study (Rodham 2004). their behaviour as 'depression'. Those who had cut themselves reported things such as being angry at themselves or wanting to relieve tension. Less than $1 \%$ of those who had cut themselves mentioned wanting to die, compared with $10 \%$ of those who had poisoned themselves. Box 2 lists the eight reasons the teenagers were asked to choose from, reordered to show the top four motives they selected. Box 3 lists evidence-based reasons for self-cutting.

Hawton \& Harriss (2004) found that young people who cut themselves were less likely to express a desire to die than those who took an overdose, less likely to seek medical attention and more likely to act impulsively - fewer individuals who cut contemplated the act for more than an hour beforehand. They reported more feelings of depression, of anger at self and of wanting relief from tension. Additionally, females who cut themselves were more likely to report that they had

B0X 3 Evidence-based reasons for selfcutting
- Psychosis
- Depression
- Obsessive-compulsive disorder
- Release from predicament or present/past trauma
- Emotion regulation/coping:
- anger, guilt or self-blame
- inadequate coping strategies
- feelings of loss of control or detachment
- alcohol and drug use
- personality disorder
- Unhealthy care-seeking
- Cultural identification 
wanted to punish themselves and had been trying to find relief from a particular state of mind.

Conte (2004) interviewed ten young women in the community about their experiences of cutting, using a grounded theory approach. They found that family problems, peer influences, co-occurring emotional/behavioural problems and cultural influences were all important factors.

\section{Are there clinical subgroups among adolescents who cut themselves?}

The National Institute for Health and Care Excellence (NICE) guidelines for the longer-term management of self-harm (National Collaborating Centre for Mental Health 2011) cite a number of studies that found certain psychological characteristics to be associated with self-harm, including cutting (Box 4).

Diagnostic groupings may be helpful in designing some interventions (e.g. cutting occurring in the context of depression), since there is an evidence base to draw from. However, not all young people who cut themselves have a mental illness. The following sections explore evidence-based explanations for cutting in young people, with subsequent discussion about possible therapeutic avenues. To avoid excluding areas of the literature, some of these sections relate to diagnostic groups, and others, in the absence of diagnosis, relate to psychosocial processes.

\section{Psychotic illness}

Patel \& Upthegrove (2009) investigated the frequency of self-harm among individuals presenting to psychiatric services with a first episode of psychosis. A high rate of self-harm was found: $32 \%$ of people referred to the service during a 1-year period had harmed themselves, predominantly by cutting. Comparison of those who presented with self-harm with those who did not suggests that teenagers (as opposed to older patients) and females are more likely to self-harm.

BOX 4 Psychological characteristics associated with self-harm

- Impulsivity

- Poor problem-solving

- Hopelessness

- Impaired positive future thinking/goal re-engagement

- High levels of self-criticism

- Perfectionism

(National Collaborating Centre for Mental Health 2011)
Nishida and colleagues (2010) investigated associations between psychotic-like experiences (subclinical hallucinatory or delusional symptoms) and self-harm. Such experiences occur not only in patients with psychotic disorders but also in people without a psychiatric diagnosis. The study found that psychotic-like experiences are associated with self-harm among 12- to 15-year-olds and that selfharm is more prevalent in young people with a greater number of psychotic-like experiences. Most commonly, however, cutting occurs without any psychotic illness or symptoms.

\section{Depressive illness}

A study of 432 children and young people with bipolar disorder revealed that about $20 \%$ engaged in some form of self-harm during a depressive episode (Esposito-Smithers 2010). Adolescents psychiatric in-patients who had cut themselves reported that self-injury helped them 'cope with feelings of depression', and depressive symptomatology was associated with the number and intensity of motivations for cutting behaviours (Kumar 2004). Menninger (1938) described self-harm as an effort to avert completed suicide, with a 'sense of relief' that suicide has been avoided (Pattison 1983).

Among secondary-school pupils, those who selfharm show higher levels of depressive and anxious symptomatology (Martin 1995; Moran 2012). However, adult studies suggest that, although some people with self-cutting behaviours have low mood or depression, many do not, and in some studies the rates are no higher than in the general population (Klonsky 2003). This suggests that there are other reasons why people cut themselves and these need alternative management strategies. There may also be a stronger association with low mood in adolescents than in adults (Ross 2002) and this relationship needs to be researched further in adolescents.

In community samples, there is a clear difference between adolescents who have attempted suicide and those who have engaged in self-injury for other reasons (Muehlenkamp 2004).

\section{Obsessive-compulsive thinking}

Several researchers have theorised about the role of obsessive and compulsive spectrum disorders and the presence of an 'addictive' quality to some self-harm behaviour in adolescents (Nixon 2002). Favazza (1998) notes that some young people cut compulsively, likening it to trichotillomania: the need to cut sets up a craving where tension builds until the young person cuts themselves, whereupon that tension is then relieved for a time. Sometimes, thoughts of the safety or harm of others accompany 
the act (Gregory 2012). Nixon et al's (2002) study of young people admitted to hospital with selfinjury reported that 41 of 42 young people had three or more addictive symptoms as defined in the World Health Organization's research diagnostic criteria for dependence syndromes.

McKay \& Andover (2011) propose that various forms of NSSI have behavioural and cognitive features in common with obsessive-compulsive disorder (OCD). There is overlap between selfreported motivations for skin-picking, which in adults include lessening feelings of tension and frustration (Arnold 1998), and self-reported motivations for cutting. Croyle \& Waltz (2007) examined characteristics associated with mildly injurious (nail-biting, skin-picking) and more injurious (cutting, burning) self-harm in a sample of young adults. Both types of self-harm were associated with some obsessive-compulsive characteristics. Yaryura-Tobias et al (1995) describe 19 women (ages 13-39) with OCD and symptoms of self-cutting. The authors suggest that there is an 'OCD subset' of people who cut themselves.

\section{Release from a predicament land associations with present or past trauma)}

Cutting or other forms of self-harm may provide temporary respite from a predicament (i.e. to avoid trauma) or a mechanism related to its aftermath (e.g. emotion regulation, see below). Young people may use self-injury to avoid or escape from difficult situations or demands, and this is the case in both those with intellectual disability (Iwata 1990; Horner 1991) and those without (Nock 2005). It may also help to reduce undesired social demands (Nock 2010).

In abusive contexts, some young people may selfinjure in an attempt to avoid punishment or abuse (Lang 2011).

Trauma may also have more lasting associations with self-harm. Many studies have found a high prevalence of past trauma, sexual abuse or neglect among young people who cut themselves (Low 2000; Gratz 2002).

Yip et al (2002) identify two groups of predictors. First, they describe 'childhood precursors' such as placement in the care system, parental divorce, serious illness and surgery, physical and sexual abuse, and impulse control disorders in family members; and second, 'adolescent conditions' such as recent loss, body alienation, substance misuse and peer conflict.

Other studies suggest increased associations with antisocial behaviour (Moran 2012). Post-traumatic stress disorder in association with cutting has also been described (Jones 1996), suggesting a relationship to trauma (e.g. sexual abuse) (Gratz 2002). Other less traumatic predicaments, including bullying, are also associated with self-harm in both genders (O’Connor 2012).

\section{Emotion regulation and coping}

In the same way that a young person may wish to avoid a predicament or situation, they may want to avoid an unwanted emotional experience (Chapman 2006), which may or may not be associated with past trauma. In adults, the wish to put an end to intolerable tension in the context of overwhelming affect emerges as a commonly reported reason for cutting (Suyemoto 1998; Yip 2002). Several studies have noted that young people report a 'sense of relief' when they cut themselves (Kumar 2004; Laye-Gindhu 2005). This affect regulation perspective involves reducing undesired emotional states (Nock 2010) or controlling emotions such as anger, anxiety, guilt or sadness in the face of stress and mounting tension (Machoian 2001; Hawton 2004).

\section{Anger and alexithymia}

Many adolescents have reported that they wanted to relieve tension prior to cutting. One US study (Rodham 2004) found that more girls than boys had been angry at themselves before cutting, whereas another reported that general anger was more common in boys (Whitlock 2011). A qualitative study involving six young people suggested that a prominent narrative for self-harm was that it directed anger inwards (Hill 2011). This may occur in the context of poor emotional communication in either the family or the individual (alexithymia), particularly poor communication between adolescent and parent (Tulloch 1997). The relationship between alexithymia and self-injury, including cutting, has been investigated in a sample of 100 female undergraduate students and the study suggests that alexithymia is a contributing factor (Paivio 2004). A more recent study in three schoolbased samples found that thought suppression and alexithymia differentiated those who self-harmed from those who did not, especially in girls (HoweMartin 2012).

\section{Feelings of loss of control and detachment}

Favazza $\&$ Conterio (1989) surveyed 240 adults who repeatedly self-harmed, reporting that $72 \%$ wanted to 'control their mind and stop it from racing' and that $65 \%$ found it relaxing. From a sample of 42 teenagers admitted to hospital with repetitive self-injury, three-quarters said that cutting released unbearable or high levels of tension (Nixon 2002). Dissociation and depersonalisation 
have been described in association with cutting in adults and young people (Klonsky 2003; Messer 2008). In these circumstances the unpleasant state of feeling detached from oneself or the world can be terminated by self-cutting (Kafka 1969; Miller 1974; Swenson 1999; Zanarini 2000).

\section{Inadequate coping strategies}

The findings described in the previous section overlap with a literature on unhealthy or inadequate coping strategies. Poor problem-solving and impulse control have been reported in adolescents who engage in self-harm (Webb 2002). Cutting as an expression of distress or a signal of protest and noncooperation has also been documented (Chapman 2006), as has difficulty in coping with setbacks (Dimmock 2008) or coping with challenges faced when exploring identity, for example about sexual orientation (O'Connor 2012).

Hall \& Place (2010b) conducted a factor analysis of self-reported coping strategies among adolescents. They identified three factors: social and active coping, seeking external solutions and non-productive coping. Cutting was most strongly correlated with not coping and tension reduction - items incorporated within the non-productive coping factor. The only factor significantly correlated with those not cutting was social and active coping, which included working hard and achieving, seeking to belong, and investing in close friendships. Interestingly, the 'seeking external solutions' factor, which included seeking professional help and focusing on the problem, was not found to correlate with self-cutting. Some young people with a limited repertoire of coping strategies may use cutting or self-harm instead of more helpful strategies.

\section{Substance use}

High-risk alcohol and cannabis use, which themselves are often seen in a coping (self-medication) context, have a higher association with self-harm in adolescence (Moran 2012). Schwartz and colleagues (1989) reported high rates of cutting in adolescent girls who misused drugs, and more recent studies continue to find that drug use is associated with self-harm in teenage girls (O'Connor 2012). Some of these young people may have unhealthy care-seeking behaviour (see below) or emerging personality disorders.

\section{Personality disorder}

Adult studies suggest that borderline personality disorder can be associated with self-cutting (Klonsky 2003), although this is complicated by the fact that predictors of self-harm in this group include coexisting depressive disorder, substance use disorder or past trauma/post-traumatic stress disorder (Wedig 2012). As this discussion demonstrates, the literature in all of these areas (discussed above) may overlap. There is some evidence that the relationship between personality and cutting may also be moderated by coping and emotion regulation (as discussed earlier) (Hasking 2010). The relationship with personality disorder is likely to be complex, influenced on the one hand by predisposing risk factors and biopsychosocial factors, and on the other by comorbid psychiatric disorders (Stepp 2012). Stigmatising terms such as 'emerging personality disorder' therefore need to be treated cautiously in the context of childhood self-harm as more careful research into these issues takes place.

\section{Unhealthy care-seeking}

Unhealthy care-seeking behaviour may be caused by both negative and positive reinforcement of cutting (Carr 1977). A young person who is struggling to cope stumbles across cutting behaviour and it elicits care or change that they find helpful. A small retrospective study explored parents' reactions to adolescent self-harm (Wagner 2000). The authors report an increase in parental feelings of caring, sadness and anxiety after discovering that their child is cutting, but often no change in hostile feelings. Although many young people cut in private, a proportion hope that someone will notice that they have done so (Whitlock 2011).

From a large European study of self-harm in children and adolescents, Scoliers and colleagues (2009) identified two underlying dimensions in the reasons for self-harm reported by participants: a 'cry of pain' motive and a ‘cry for help' motive. The majority of adolescents reported at least one cry of pain motive (e.g. 'to get relief from a terrible state of mind'; see 'Emotion regulation and coping') and an additional cry for help motive (e.g. 'to show how desperate I was feeling', 'to get some attention'). This accords with adult studies which find that the majority of individuals reported seeking a more general helping response from people in their close environment (e.g. practical support) rather than professional help.

A qualitative study of three adolescent girls in a residential unit (Machoian 2001) suggests that the inability to be heard by those around them is a relevant narrative. Some young people experience greater tolerance, time, listening or care when they have cut themselves. One study of 400 selfinjury message boards on the internet found that they are helpful in providing support to isolated young people, but raises concerns that they may also normalise or even encourage self-harming behaviour (Whitlock 2006). 


\section{Cultural identification}

Derouin \& Bravender (2004) suggest that there exists a subgroup of adolescents engaging in cutting who are apparently mentally well adjusted and achieving at school (Whitlock 2011). Many develop an identification with others who cut themselves (Favazza 1998).

Dimmock and colleagues (2008) used interviews to gather information from different groups who cut themselves. These included young people attending mental health services, young people whose teachers knew that they cut themselves regularly, and pupils of a large secondary school. Several young people who were identified as cutting regularly stressed the role that cutting plays within their peer group. A social perspective looks at the influence of leaders within peer culture and contagion of cutting (Hawton 2012). Among adolescent in-patients, for example, self-harm can be a mechanism to promote belonging and is sometimes driven by competitiveness (Taiminen 1998). A study of 6000 adolescents (Hawton 2010) found that far more of those who had self-harmed in the previous year had friends who had also self-harmed in the same period and that contagion may be particularly important among girls who cut themselves. These results were replicated in a study of 2008 teenagers in Scotland and Ireland (O'Connor 2012).

The media have linked goth and emo youth subcultures with self-harm, but research in this area is sparse. A longitudinal study of 1258 11- to 19-year-old goths (Young 2006) found a prevalence of cutting of $47 \%$, suggesting that goth identification at that time was strongly associated with self-harm. However, the direction of association remains unclear. It is possible that young people with a propensity to cutting are attracted to goth subculture; alternatively, cutting could be a normative component of the subculture, influenced by factors such as emulation of associated icons known to self-harm.

The media and increasing social networking are likely to be an important conduit for cultural identification (Hawton 2012).

\section{Treatment approaches}

Moran and colleagues (2012) conducted a longitudinal study charting the natural history of self-harm. The study suggests that a proportion of self-harming behaviour in adolescents resolves spontaneously. However, early detection and management of common mental health difficulties during adolescence may not only serve to reduce rates of self-harm in adolescence itself, but may also contribute to the prevention of suicide in young adults.
A plethora of treatment approaches have been used to help young people who cut themselves, including individual, family and group therapy, music therapy, assertiveness training, communication skills training and medication (Derouin 2004; Burns 2005). There is limited research on which treatments are effective and for which groups. Pryjmachuk \& Trainor (2010) reviewed the literature and concluded that therapist preferences, rather than an evidence base, are often the driving force behind interventions offered for self-harm.

There are diverse causes and associations of cutting. Given this, we build a case below, based on the growing evidence base for therapeutic interventions, for a more tailored approach to the young person and their individual situation. The following are some therapeutic options to consider. Although we have grouped them under specific subheadings, they may be helpful in a range of different contexts.

\section{Depression}

Cognitive-behavioural therapy, interpersonal therapy and medication

As noted in the NICE guidelines on depression in children and young people (National Institute for Health and Clinical Excellence 2005), the largest evidence base for psychological therapy is for cognitive-behavioural therapy (CBT), with less evidence for family therapy and less still to confirm or refute the effectiveness of individual child psychotherapy.

As regards pharmacological treatments used as an adjunct to psychological therapies, NICE concluded that fluoxetine should be the first-line selective serotonin reuptake inhibitor (SSRI) antidepressant. It recommends sertraline or citalopram if fluoxetine is ineffective or not tolerated.

There is debate about whether SSRIs may increase the risk of suicidal ideation in young people. One study found a reduction in suicidality when CBT was added to fluoxetine (Emslie 2006), but another did not (Goodyer 2007). Evidence indicates that fluoxetine in combination with CBT is more effective in reducing depressive symptoms and producing global clinical improvement; the combination of treatments may also mitigate against any increase in suicidal ideation associated with fluoxetine.

The issue of cutting in depression and how this is affected by serotonin reuptake inhibitors requires further research. Although SSRIs may be helpful in depression, currently NICE guidance does not recommend SSRIs as a specific treatment for selfharm (National Institute for Health and Clinical Excellence 2004; National Collaborating Centre 
for Mental Health 2011). In addition, some young people perceive medication as a way of 'fobbing them off' (Storey 2005).

Interpersonal therapy is also a recommended treatment for depression, and an adapted form has been suggested for young people who self-harm, although further research is needed to test its efficacy (Jacobson 2012).

\section{Psychosis}

Acts of self-harm occurring during a psychotic episode may present as more violent than in other circumstances (DeHert 2001). Guidelines developed by work groups in the USA are based on reviews of the literature and a consensus of expert advice (Kowatch 2005). They discuss the importance of careful risk assessment and review to assess whether in-patient support may be necessary. They also suggest that evidence to date on the efficacy of lithium in bipolar disorder is compelling. They highlight the importance of involving the family and suggest that specific psychosocial therapies for the management of ongoing self-harm, such as dialectic behavioural therapy (DBT) should be considered.

In its recent guideline on psychosis and schizophrenia in children and young people (National Institute for Health and Clinical Excellence 2013), NICE refers clinicians to its guideline on selfharm (National Institute for Health and Clinical Excellence 2004) for advice on managing acts of self-harm in children and young people over 8 years of age.

\section{Obsessive-compulsive disorder}

Where cutting is associated with obsessivecompulsive characteristics, interventions to treat OCD may be beneficial. There is a strong evidence base for the efficacy of CBT for young people with OCD (National Institute for Health and Clinical Excellence 2005). The NICE guidelines state that children and young people with OCD with moderate to severe functional impairment should be offered CBT including exposure and response prevention. Treatment should involve the family or carers and be adapted to suit the developmental age of the child. If CBT has not provided adequate relief of symptoms, the addition of an SSRI to ongoing psychological treatments may be considered following multidisciplinary review.

\section{Emotion regulation therapies and therapies that improve coping or healthy care-seeking}

Rodham et al (2004) argue that, given the considerable numbers of young people who cut themselves, clinical management should focus on prevention by encouraging alternative methods of managing distress, problem-solving and helpseeking. Compatible with this might be an approach that models and informs alternative, healthy careseeking behaviours, positive coping and social problem-solving strategies; this could be in a family context, or in individual or group therapy.

\section{Dialectical behaviour therapy}

It has been suggested that DBT reduces selfharm. However, most research has focused on the reduction of suicidal behaviour in individuals with a diagnosis of borderline personality disorder (Klonsky 2007). Using DBT, which combines elements of CBT with emotion regulation and meditative techniques, James and colleagues (2008) found a marked reduction in self-reported episodes of self-harm, which was maintained at 8-month follow-up. However, this was a small study lacking a control group.

Many believe that DBT is promising, but further research is needed into this and other therapies that include emotion regulation. There are to date no randomised controlled trials (RCTs) of DBT in self-harm, although it has been adapted for suicidal adolescents (Rathus 2002).

\section{Cognitive-behavioural therapy}

Research focusing specifically on the efficacy of CBT for self-harm among young people (rather than for depression) is limited (Ougrin 2012). An RCT comparing CBT with treatment as usual (TAU) provides evidence that time-limited CBT is effective for older adolescents and adults with recurrent and chronic self-harm (Slee 2008). Given the evidence of a stronger association between self-harm and low mood in adolescents than in adults, and strong evidence for the efficacy of CBT for adolescents with low mood and depression (Compton 2004; National Institute for Health and Clinical Excellence 2005), further research specifically evaluating CBT for young people who cut themselves is warranted. Cognitive-behavioural therapy is an ideal therapeutic modality for the development of healthy coping strategies.

\section{Social problem-solving therapies}

Research evaluating problem-solving therapy for young people who self-harm through cutting is sparse. However, there is evidence to suggest that problem-solving therapy is appropriate for young people who attempt suicide, especially where there is an element of impulsivity (Brent 1997). A meta-analysis of RCTs investigating the efficacy of problem-solving treatments for selfharm in adults concluded that problem-solving therapy was more effective than TAU (Townsend 
2001). Problem-solving may include suggesting alternatives to the act of cutting itself (e.g. using rubber bands to snap on the wrist or holding ice cubes) or equipping the young person with social problem-solving skills for life's challenges (Manassis 2012). Anderson and colleagues (2004) suggest that more qualitative research is needed into what young people and families find useful.

\section{Psychoeducation}

Educational programmes promoting a more communicative relationship with significant others may be helpful in reducing the prevalence of selfharming behaviour. Hawton et al (2006) suggest that a successful mental health programme should address managing difficulties faced by young people and equipping them with coping skills. There are growing numbers of educative self-help websites for adolescents with mental health problems.

\section{Group therapy}

Young people who cut themselves often describe feelings of isolation or not 'fitting in', thus a group approach may be a helpful intervention for some. Group therapy can be underpinned by a number of different frameworks, but developmental group psychotherapy is the only group approach designed specifically for young people who self-harm (Burns 2005). It is currently the only intervention recommended by NICE (National Institute for Health and Clinical Excellence 2004) for young people who repeatedly self-harm.

Developmental group psychotherapy is an eclectic approach influenced by CBT, DBT and psychodynamic group psychotherapy. The focus is on recovery and development, covering themes such as bullying, family/relationship difficulties, problem-solving, communication and mood, as well as self-harm more directly.

Evidence for the efficacy of developmental group psychotherapy is limited. A pilot RCT conducted by Wood et al (2001) found that developmental group psychotherapy had a significant effect on repeated self-harm when compared with TAU. However, Hazell et al (2009) were unable to replicate this finding in an Australian sample. Green et al (2011) conducted a full-scale RCT with economic evaluation, concluding that the addition of developmental group psychotherapy to TAU did not improve outcomes for adolescents who repeatedly self-harm, and that there is limited evidence for cost-effectiveness.

\section{Family therapy}

Qualitative work suggests that supportive parents and family can help young people resolve interpersonal issues related to cutting (Yip 2003). Harrington and colleagues (1998) conducted an RCT of a home-based intervention for young people who had poisoned themselves. The intervention consisted of an assessment session and four home visits by social workers to conduct family problem-solving sessions. Overall, there was no significant difference between the TAU group and the TAU-plus-family-intervention group. However, the findings suggested that home-based family intervention may be beneficial for young people who harm themselves but who do not have depression. This is encouraging given our knowledge that many young people who cut themselves may not have depression, but may be struggling with coping and care-seeking behaviours.

A large multicentre RCT is currently underway, looking at family therapy as a treatment for young people who repeatedly self-harm (Cottrell 2012).

\section{Multisystemic therapy}

Multisystemic therapy (MST) focuses on improving parenting and generating enhanced community supports for young people. It is used in youth offending and other contexts. One study randomised adolescents to either MST or admission to a psychiatric hospital. Those in the MST group had fewer episodes of attempted suicide 1 year later (Huey 2005). However, this study was not specifically targeted at people who cut themselves. Multisystemic therapy may have a role for young people who repeatedly self-harm but, like CBT and DBT, requires RCTs to test its efficacy (Ougrin 2012).

\section{Conclusions}

There is an important role for communities, the media and policy makers in the prevention of selfharm (Hawton 2012), but we have focused here on cutting and interventions targeted at child and family. Terms such as self-mutilation are clinically unsatisfactory. DSM- 5 creates a stand-alone category for 'non-suicidal self-injury' (NSSI), involving bodily injury that is not suicidal or socially related (such as piercing or tattooing). It proposes that this clarity of definition will allow future research (American Psychiatric Association 2013). As Andover et al (2012) point out, most groups described by various nomenclatures are heterogeneous. A good example of this is the ambiguous and fluctuating attitude that many young people who cut have towards suicidal intent. Exploring the context and motivations of cutting is a pragmatic way of finding the best intervention for each young person. It sees each young person as an individual and leads to the design of therapies accordingly. Children and 
young people also cut themselves in a family, peer, social and cultural context (Yip 2005) and these influences need to be carefully considered. Services that use diagnosis as a threshold for entry to child and adolescent mental health service therapies may need to review this if the prevention of longer-term difficulties (Chanen 2012) is to be achieved. Above all, more methodologically sound research needs to be conducted to design and evaluate better-targeted preventive and treatment interventions for young people who cut their own skin.

\section{Appendix: Other sources consulted}

Brezo J, Paris J, Turecki G (2005) Personality traits as correlates of suicidal ideation, suicide attempts, and suicide completions: a systematic review. Acta Psychiatrica Scandinavica 11: 180-206.

Brophy M (2006) Truth Hurts: Report of the National Enquiry into Selfharm Among Young People. Mental Health Foundation.

DiClemente CC, Prochaska J0, Fairhurst SK, et al (1991) The process of smoking cessation: an analysis of precontemplation, contemplation and preparation stages of change. Journal of Consulting and Clinical Psychology 59: 295-304.

Hawton K, Townsend E, Arensman E, et al (2000) Psychosocial versus pharmacological treatments for deliberate self harm. Cochrane Database of Systematic Reviews 2: CD001764.

Himber J (1994) Blood rituals: self-cutting in female psychiatric inpatients. Psychotherapy 31: 123-38.

MacLeod AK, Pankhania B, Lee M, et al (1997) Parasuicide, depression and anticipation of positive and negative future experiences. Psychological Medicine 27: 973-7.

Milligan RJ, Waller G (2001) Anger and impulsivity in non-clinical women. Personal Individual Difference 30: 1073-8.

O'Connor RC, Rasmussen S, Hawton K (2009) Predicting deliberate selfharm in adolescents: a six month prospective study. Suicide and LifeThreatening Behavior 39: 364-75.

Pao PN (1969) The syndrome of deliberate self cutting. British Journal of Medical Psychology 42: 195-206.

Ross RR, McKay HB (1979) Self-Mutilation. Lexington Books.

Walsh BW, Rosen PM (1988) Self-Mutilation: Theory, Research and Treatment. Guilford Press.

Yaroshevsky F (1975) Self-mutilation in Soviet prisons. Canadian Psychiatric Association Journal 20: 443-6.

\section{References}

American Psychiatric Association (2013) Diagnostic and Statistical Manual of Mental Disorders (5th edn) (DSM-5). APA.

Anderson M, Woodward L, Armstrong M (2004) Self-harm in young people: a perspective for mental health nursing care. International Council of Nurses, International Nursing Reviews 51: 222-8.

Andover MS, Morris BW, Wren A, et al (2012) The co-occurrence of non-suicidal self-injury and attempted suicide among adolescents: distinguishing risk factors and psychosocial correlates. Child and Adolescent Psychiatry and Mental Health 6: 1-7.

Arnold LM, McElroy SL, Mutasim DF, et al (1998) Characteristics of 34 adults with psychogenic excoriation. Journal of Clinical Psychiatry 59: 509-14

Brent DA, Holder D, Kolko D, et al (1997) A clinical psychotherapy trial for adolescent depression comparing cognitive, family, and supportive treatment. Archives of General Psychiatry 54: 877-85.

Burns J, Dudley M, Hazell P, et al (2005) Clinical management of deliberate self-harm in young people: the need for evidence based approaches to reduce repetition. Australian and New Zealand Journal of Psychiatry 39: 121-8.
Carr EG (1977) The motivation of self-injurious behavior. Psychological Bulletin 84: 800-16.

Chanen AN, Kaess M (2012) Developmental pathways to borderline personality disorder. Current Psychiatry Reports 14: 45-53.

Chapman AL, Gratz KL, Brown ML (2006) Solving the puzzle of deliberate self-harm: the experiential avoidance model. Behaviour Research and Therapy 44: 371-94.

Compton SN, March JS, Brent D, et al (2004) Cognitive-behavioural psychotherapy for anxiety and depressive disorders in children and adolescents: an evidence-based medicine review. Journal of the American Academy of Child and Adolescent Psychiatry 43: 930-59.

Conte S-A (2004) Speaking for Themselves: A Qualitative Study of Young Women who Self-Injure: 286. New York University, School of Social Work

Cottrell D, Boston P, Eisler I, et al (2012) SHIFT. Self-Harm Intervention, Family Therapy: A Randomised Controlled Trial of Family Therapy vs. Treatment as Usual for Young People seen after Second or Subsequent Episodes of Self-Harm. Health Technology Assessment Programme, NHS National Institute for Health Research (http://www.hta.ac.uk/ protocols/200700330001.pdf)

Croyle KL, Waltz J (2007) Subclinical self-harm: range of behaviours, extent, and associated characteristics. American Journal of Orthopsychiatry 77: 332-42.

De Hert M, McKenzie K, Peuskens J (2001) Risk factors for suicide in young people suffering from schizophrenia: a long-term follow-up study. Schizophrenia Research 47: 127-34.

Derouin A, Bravender T (2004) Living on the edge, the current phenomenon of self-mutilation in adolescents. MCN The American Journal of Maternal Child Nursing 29: 12-20.

Dimmock M, Grieves S, Place M (2008) Young people who cut themselves - a growing challenge for educational settings. British Journal of Special Education 35: 42-8.

Emslie G, Kratochvil C, Vitiello B, et al (2006) Treatment for adolescents with depression study (TADS): safety results. Journal of the American Academy of Child and Adolescent Psychiatry 45: 1440-55.

Esposito-Smithers C, Goldstein T, Birmaher B, et al (2010) Clinical and psychosocial correlates of non-suicidal self-injury within a sample of children and adolescents with bipolar disorder. Journal of Affective Disorders 125: 89-97.

Favazza A, Conterio K (1989) Female habitual self mutilators. Acta Psychiatrica Scandinavica 79: 282-9.

Favazza A (1998) The coming of age of self-mutilation. Journal of Nervous and Mental Diseases 186: 259-68.

Friedman T, Newton C, Coggan C, et al (2006) Predictors of A\&E staff attitudes to self harm patients who use self laceration: influence of previous training and experience. Journal of Psychosomatic Research 60: $273-7$

Goodyer I, Dubicka B, Wilkinson P, et al (2007) Selective serotonin reuptake inhibitors (SSRIs) and routine specialist care with and without cognitive behaviour therapy in adolescents with major depression: randomised controlled trial. BMJ 335: 142.

Gratz KL, Dukes-Conrad SD, Roemer L (2002) Risk factors for deliberate self-harm among college students. American Journal of Orthopsychiatry 72: $128-40$.

Green JM, Wood AJ, Kerfoot MJ, et al (2011) Group therapy for adolescents with repeated self harm: randomised controlled trial with economic evaluation. BMJ 342: d682.

Gregory RJ, Mustata GT (2012) Magical thinking in narratives of adolescent cutters. Journal of Adolescence 35: 1045-51.

Hall B, Elliott J, Place M (2010a) Self-harm through cutting. Evidence from a sample of schools in the north of England. Pastoral Care in Education 28: 33-43.

Hall B, Place M (2010b) Cutting to cope - a modern adolescent phenomenon. Child: Care, Health and Development 36: 623-9.

Harrington R, Kerfoot M, Dyer E, et al (1998) Randomized trial of homebased family intevention for children who have deliberately poisoned themselves. Journal of the American Academy of Child and Adolescent Psychiatry 37: 512-8. 
Hasking PA, Coric SJ, Swannell S, et al (2010) Emotion regulation and coping as moderators in the relationship between personality and self injury. Journal of Adolescence 33: 767-73.

Hawton K, Fagg J, Simkin S (1996) Deliberate self-poisoning and selfinjury in children and adolescents under 16 years of age in 0xford, 1976-1993. British Journal of Psychiatry 169: 202-8.

Hawton K, Rodham K, Evans E (2002) Deliberate self-harm in adolescence: a self-report survey in Schools in England. BMJ 325: 1207-11.

Hawton K, Harriss L (2004) Self-cutting patient characteristics compared with self-poisoners. Suicide and Life-Threatening Behavior 34: 199-208.

Hawton K, Rodham R, Evans E (2006) By Their Own Young Hand: Deliberate Self-Harm and Suicidal Ideas in Adolescents. Jessica Kingsley Publishers.

Hawton K, Harriss L, Rodham K (2010) How adolescents who cut themselves differ from those who take overdoses. European Child and Adolescent Psychiatry 19: 513-23.

Hawton K, Saunders KEA, O'Connor RC (2012) Self-harm and suicide in adolescents. Lancet 379: 2373-82.

Hazell PL, Martin G, McGill K, et al (2009) Group therapy for repeated deliberate self-harm in adolescents: failure of replication of a randomized trial. Journal of the American Academy of Child and Adolescent Psychiatry 48: 662-70.

Hill K, Dallos R (2011) Young people's stories of self-harm: a narrative study. Clinical Child Psychology and Psychiatry 17: 459-75.

Horner RH, Day HM, Sprague JR, et al (1991) Interspersed requests: a non-aversive procedure for reducing aggression and self-injury during instruction. Journal of Applied Behavioural Analysis 24: 265-78.

Howe-Martin LS, Murrell AR, Guarnaccia CA (2012) Repetitive nonsuicidal self-injury as experiential avoidance among a community sample of adolescents. Journal of Clinical Psychology 7: 809-29.

Huey S, Henggeler S, Rowland M, et al (2005) Predictors of treatment response for suicidal youth referred for emergency psychiatric hospitalization. Journal of Clinical Child and Adolescent Psychology 34: 582-9.

Iwata BA, Pace GM, Kalsher MJ, et al (1990) Experimental analysis and extinction of self-injurious behaviour. Journal of Applied Behavior Analysis 23: 11-27.

Jacobson CM, Mufson L (2012) Interpersonal psychotherapy for depressed adolescents adapted for self-injury (IPT-ASI): rationale, overview and case summary. American Journal of Psychotherapy 66: 349-74.

James AC, Taylor A, Winmill L, et al (2008) A preliminary community study of dialectical behaviour therapy (DBT) with adolescent females demonstrating persistent, deliberate self-harm (DSH). Child and Adolescent Mental Health 13: 148-52.

Jeffery D, Warm A (2002) A study of service providers' understanding of self-harm. Journal of Mental Health 11: 295-303.

Jones IH, Daniels BA (1996) An ethological approach to self-injury. British Journal of Psychiatry 169: 263-7.

Kafka JS (1969) The body as a transitional object: a psychoanalytic study of a self-mutilating patient. British Journal of Medical Psychology 42 : 207-12.

Klonsky ED, Oltmanns TF, Turkheimer E (2003) Deliberate self-harm in a non-clinical population: prevalence and psychological prevalence. American Journal of Psychiatry 160: 1501-8.

Klonsky ED, Muehlenkamp JJ (2007) Self-injury: a research review for the practitioner. Journal of Clinical Psychology 63: 1045-56.

Kowatch RA, Fristad M, Birmaher B, et al (2005) Treatment guidelines for children and adolescents with bipolar disorder. Journal of the American Academy of Child and Adolescent Psychiatry 44: 213-35.

Kumar G, Pepe D, Steer RA (2004) Adolescent psychiatric in-patients self reported reasons for cutting themselves. Journal of Nervous and Mental Disease 192: 830-6.

Lang CM, Sharma-Patel K (2011) The relation between childhood maltreatment and self-injury: a review of the literature on conceptualization and intervention. Trauma, Violence and Abuse 12: 23-37.
Laukkanen E, Rissanen ML, Honkalampi K, et al (2009) The prevalence of self-cutting and other self-harm among 13 to 18 year old Finnish adolescents. Social Psychiatry and Psychiatric Epidemiology 44: 23-8.

Laye-Gindhu A, Schonert-Reichl KA (2005) Non-suicidal self-harm among community adolescents: understanding the "whats" and "whys" of self harm. Journal of Youth and Adolescence 34: 447-57.

Low G, Jones D, MacLeod A, et al (2000) Childhood trauma, dissociation and self-harming behaviour: a pilot study. British Journal of Medical Psychology 73: 269-78.

Machoian L (2001) Cutting voices, self injury in three adolescent girls. Journal of Psychosocial Nursing and Mental Health Services 39: 22-9.

Manassis K (2012) Problem Solving in Child and Adolescent Psychotherapy: A Skills Based Collaborative Approach. Guilford Press.

Martin G, Rotaries P, Pearce C, et al (1995) Adolescent suicide, depression and family dysfunction. Acta Psychiatrica Scandinavica 92: 336-44.

McAllister M (2003) Multiple meanings of self harm: a critical review. International Journal of Mental Health Nursing 12: 177-85.

McKay D, Andover M (2011) Should nonsuicidal self-injury be a putative obsessive-compulsive-related condition? A critical appraisal. Behaviour Modification 36: 3-17

Menninger K (1938) Man Against Himself. Harcourt Brace \& World.

Messer JM, Fremouw WJ (2008) A critical review of explanatory models for self-mutilating behaviours in adolescents. Clinical Psychology Review 28: 162-78.

Miller F, Bashkin E (1974) Depersonalisation and self-mutilation. Psychoanalytic Quarterly 43: 638-49.

Moran P, Coffey C, Romaniuk H, et al (2012) The natural history of selfharm from adolescence to young adulthood: a population-based cohort study. Lancet 379: 236-43.

Muehlenkamp JJ, Gutierrez PM (2004) An investigation of differences between self-injurious behaviour and suicide attempts in a sample of adolescents. Suicide and Life-Threatening Behavior 34: 12-23.

National Collaborating Centre for Mental Health (2011) Self-Harm: The NICE Guideline on Longer-Term Management (National Clinical Guideline Number 133). British Psychological Society and Royal College of Psychiatrists.

National Institute for Health and Clinical Excellence (2004) Self-Harm: The Short-Term Physical and Psychological Management and Secondary Prevention of Self-Harm in Primary and Secondary Care (Clinical Guideline CG16). NICE.

National Institute for Health and Clinical Excellence (2005) Depression in Children and Young People: Identification and Management in Primary, Community and Secondary Care (Clinical Guideline CG28). NICE.

National Institute for Health and Clinical Excellence (2013) Psychosis and Schizophrenia in Children and Young People: Recognition and Management (NICE Clinical Guideline 155). NICE.

Nishida A, Sasaki T, Nishimura Y, et al (2010) Psychotic-like experiences are associated with suicidal feelings and deliberate self-harm behaviors in adolescents aged 12-15 years. Acta Psychiatrica Scandinavica 121: $301-7$.

Nixon MK, Cloutier PF, Agarwal S (2002) Affect regulation and addictive aspects of repetitive self-injury in hospitalized adolescents. Journal of the American Academy of Child and Adolescent Psychiatry 41: 1333-41. Nock MK, Prinstein MJ (2005) Contextual features and behavioural functions of self-mutilation among adolescents. Journal of Abnormal Psychology 114: 140-6.

Nock MK (2010) Self injury. Clinical Psychology 6: 339-63.

O'Connor RC, Rasmussen S, Hawton K (2012) Distinguishing adolescents who think about self-harm from those who engage in self-harm. British Journal of Psychiatry 200: 330-5.

Ougrin D, Tranah T, Leigh E, et al (2012) Practitioner review: self-harm in adolescents. Journal of Child Psychology and Psychiatry 53: 337-50.

Paivio SC, McCulloch CR (2004) Alexithymia as a mediator between childhood trauma and self-injurious behaviours. Child Abuse and Neglect 28: 339-54.

Patel K, Upthegrove R (2009) Self-harm in first-episode psychosis. Psychiatric Bulletin 33:104-7

\section{MCO answers \\ $1 d \quad 2 d \quad 3$ b 4 e $5 c$}


Pattison EM, Kahan J (1983) The deliberate self-harm syndrome. American Journal of Psychiatry 140: 867-72.

Patton GC, Harris R, Carlin JB, et al (1997) Adolescent suicidal behaviours: a population-based study of risk. Psychological Medicine 27: 715.

Pryjmachuk S, Trainor G (2010) Helping young people who self-harm: perspectives from England. Journal of Child and Adolescent Psychiatric Nursing 23: 52-60.

Rathus JH, Miller AL (2002) Dialectic behaviour therapy adapted for suicidal adolescents. Suicide and Life-Threatening Behavior 32: 146-57.

Rodham K, Hawton K, Evans E (2004) Reasons for deliberate self-harm: comparison of self-poisoners and self-cutters in a community sample of adolescents. Journal of the American Academy of Child and Adolescent Psychiatry 43: 80-7

Ross S, Heath N (2002) A study of the frequency of self-mutilation in a community sample of adolescents. Journal of Youth and Adolescence 31: $67-77$

Saunders K, Hawton K, Fortune S, et al (2011) Attitudes and knowledge of clinical staff regarding people who self-harm: a systematic review. Journal of Affective Disorders 139: 205-16.

Schwartz RH, Cohen P, Hoffmann NG, et al (1989) Self-harm behaviors (carving) in female adolescent drug abusers. Clinical Pediatrics 28: 340-6.

Scoliers G, Portzky G, Madge N, et al (2009) Reasons for adolescent deliberate self-harm: a cry of pain and/or a cry for help? Findings from the child and adolescent self-harm in Europe (CASE) study. Social Psychiatry and Psychiatric Epidemiology 44: 601-7.

Slee N, Garnefski N, van der Leeden R, et al (2008) Cognitive-behavioural intervention for self-harm: randomised controlled trial. British Journal of Psychiatry 192: 202-11.

Stepp SD (2012) Development of borderline personality disorder in adolescence and young adulthood: introduction to the special section. Journal of Abnormal Child Psychology 40: 1-5.

Storey P, Hurry J, Jowitt S, et al (2005) Supporting young people who repeatedly self-harm. Perspectives in Public Health 125: 71-5.

Suyemoto KL (1998) The functions of self-mutilation. Clinical Psychology Review 18: 531-54.

Swenson KL (1999) A Bright Red Scream: Self-Mutilation and the Language of Pain [book review]. Psychiatric Services 50: 1234-5.

Taiminen TJ, Kallio-Soukainen K, Noksokoivisto H, et al (1998) Contagion of deliberate self-harm among adolescent inpatients. Journal of the American Academy of Child and Adolescent Psychiatry 3: 211-21.

Taylor TL, Hawton K, Fortune S, et al (2009) Attitudes towards clinical services among people who self-harm: systematic review. British Journal of Psychiatry 194: 104-10.
Townsend E, Hawton K, Altman DG, et al (2001) The efficacy of problem-solving treatments after deliberate self-harm: meta-analysis of randomized controlled trials with respect to depression, hopelessness and improvement in problems. Psychological Medicine 31: 979-88.

Tulloch AL, Blizzard L, Pinkus S (1997) Adolescent-parent communication in self-harm. Journal of Adolescent Health 21: 267-75.

Wagner B, Aiken C, Mullaley MA (2000) Parents' reactions to adolescents' suicide attempts. Journal of the American Academy of Child and Adolescent Psychiatry 39: 429-36.

Webb $L$ (2002) Deliberate self-harm in adolescence: a systematic review of psychological and psychosocial factors. Journal of Advanced Nursing 38: 235-44.

Wedig MM, Silverman MH, Frankenburg FR, et al (2012) Predictors of suicide attempts in patients with borderline personality disorder over 16 years of prospective follow up. Psychological Medicine 42: 2395-404.

Whitlock JL, Powers JL, Eckenrode J (2006) The virtual cutting edge: the internet and adolescent self injury. Developmental Psychology 42: 407-17

Whitlock J, Muehlenkamp J, Purington A, et al (2011) Non-suicidal selfnjury in a college population: general trends and sex differences. Journal of American College Health 59: 691-8.

Wood A, Trainor G, Rothwell J, et al (2001) Randomised trial of group therapy for repeated deliberate self-harm in adolescents. Journal of the American Academy of Child and Adolescent Psychiatry 40: 1246-53.

Yaryura-Tobias JA, Neziroglu FA, Kaplan S (1995) Self-mutilation, anorexia, and dysmenorrhea in obsessive compulsive disorder. International Journal of Eating Disorders 17: 33-8.

Yip K, Ngam M, Lam I (2002) An explorative study of peer influence and response to adolescent self-cutting behavior in Hong Kong. Smith Studies in Social Work 72: 379-401.

Yip K, Ngan M, Lam I (2003) A qualitative study of parental influence on and response to adolescents' self-cutting in Hong Kong. Families in Society 84: 405-16.

Yip K (2005) A multi-dimensional perspective of adolescents' self-cutting. Child and Adolescent Mental Health 10: 80-6.

Young R, Sweeting H, West $\mathrm{P}$ (2006) Deliberate self harm and attempted suicide with contemporary Goth youth subculture: Iongitudinal cohort study. BMJ 332: 1058-61.

Young Minds (2012) Talking Taboos - Talking Self-Harm. Cello Group.

Zanarini M, Ruser T, Frankenburg FR (2000) The dissociative experience of borderline patients. Comprehensive Psychiatry 41: 223-35.

\section{MCOs}

Select the single best option for each question stem

1 Young people who cut themselves:

a often raise feelings of sympathy in the professionals who come across them

b should be treated as a homogeneous group in terms of interventions

c are likely to attend the emergency department after cutting themselves

$d$ may have a range of different motivations or aetiologies

e usually have a mental illness.

2 Usual first-line treatment for mild/ moderate depression in a 15 -year-old is:

a fluoxetine

b citalopram c counselling

d CBT

e family therapy.

3 In self-cutting, the term contagion describes:

a infection of the cut

b influence on one person by another

c using a dirty needle or knife that another person has used

$\mathrm{d}$ a social perspective

e fear of telling others about cutting behaviour.

4 First-line treatment for self-cutting in a 12-year-old boy who has OCD would not usually include:

a CBT

b exposure c response prevention

$\mathrm{d}$ work with the family

e paroxetine.

5 Initial treatment for a 13-year-old girl where cutting has become a means of eliciting care for herself would usually include:

a admission to hospital

b fluoxetine

c work with the family on reinforcing alternative care-seeking strategies

d psychodynamic psychotherapy

e aversion therapy. 